\title{
Rapid method for generating designer algal mitochondrial genomes
}

Ryan R. Cochrane ${ }^{1}$, Stephanie L. Brumwell ${ }^{1}$, Maximillian P.M. Soltysiak ${ }^{1}$, Samir Hamadache ${ }^{1}$, Jennifer G. Davis ${ }^{1}$, Jiayi Wang ${ }^{1}$, Samuel Q. Tholl ${ }^{1}$, Preetam Janakirama ${ }^{2}$, David R. Edgell ${ }^{1}$, and Bogumil J. Karas ${ }^{1,2^{*}}$.

${ }^{1}$ Department of Biochemistry, Schulich School of Medicine and Dentistry, The University of Western Ontario, London, N6A 5C1, Ontario, Canada

${ }^{2}$ Designer Microbes Inc., London, Ontario, Canada

*Correspondence: bkaras@uwo.ca

Keywords: Mitochondria, Synthetic Organelles, Transformation-Associated Recombination Cloning, Diatom, Eukaryotic Algae, Whole Genome Cloning, Phaeodactylum tricornutum

\section{HIGHLIGHTS}

- TAR-cloned mitochondrial genome of $P$. tricornutum in yeast

- Developed PCR-based cloning method to create designer algal mitochondrial genomes

- Stably propagated algal mitochondrial genomes in $S$. cerevisiae and $E$. coli hosts 


\section{ABSTRACT}

With synthetic biology, we can turn algae into bio-factories that produce high-value molecules (e.g. medicines or biofuels) or tackle global challenges (e.g. malnutrition and climate change). This realization has provoked rapid progress towards the creation of genetic tools for multiple algal species, notably Phaeodactylum tricornutum. The power of synthetic biology to generate more useful or productive organisms is contingent on the ability to produce diverse DNA molecules and rapidly screen them for beneficial variants. However, it is still relatively expensive to synthesize DNA, and delivering large DNA (>50 kbp) to eukaryotic cellular compartments remains challenging. In this study, we establish a robust system for building algal mitochondrial genomes as a practical alternative to DNA synthesis. Our approach permits an inexpensive and rapid generation of mitochondrial derivatives designed for testing targeted DNA delivery. First, we cloned the mitochondrial genome of $P$. tricornutum into the eukaryotic host organism $S$. cerevisiae using two different techniques: transformation-associated recombination; and PCR-based cloning. Next, we analyzed the cloned genomes by multiplex PCR, and correct genomes were transferred to prokaryotic host $E$. coli. Then these genomes were again analyzed by multiplex PCR, followed by diagnostic digest and complete-plasmid sequencing to evaluate the fidelity of each cloning method. Finally, we assessed the burden on eukaryotic and prokaryotic hosts to propagate the cloned genomes. We conclude that our system can reliably generate variants for genome-level engineering of algal mitochondria.

\section{Introduction}

Pressing challenges in agriculture, medicine, and energy can be addressed through the use of designer organisms with engineered traits. The promise of synthetic biology lies in the ability to 
build, deliver, and install synthetic genomes and biosynthetic pathways in specialized hosts. Phaeodactylum tricornutum is a model diatom algal species that is an attractive candidate for synthetic biology applications [1-6]. For example, $P$. tricornutum is a popular candidate for biofuel production due to its natural propensity for lipid storage [7]. Due to the industrial and academic interest in this algal species, its genomes (nuclear, mitochondrial, and plastid) were sequenced [810]. The availability of genome sequences allowed for the development of genetic tools and DNA delivery methods such as biolistic-mediated transformation [11,12], electroporation [13-15] and bacterial conjugation [16,17]. Additional tools for $P$. tricornutum include a method for cloning whole chromosomes in yeast and Escherichia coli [18], characterized centromeres for maintaining episomal DNA [19], and genome-editing technologies [6,20-22]. We now have a powerful arsenal of tools for engineering algal nuclear genomes; however, tools for engineering and delivering organelle genomes are still lacking.

There are several advantages of engineering organelle genomes and installing synthetic DNA in these compartments rather than the nucleus. First, the polycistronic gene organization, lack of transgene silencing, and reduced positional effects in organellar DNA simplify genome engineering relative to the nucleus. Second, organelles allow for the compartmentalization of biosynthetic pathways, which isolates toxic intermediates, increases flux, and minimizes competing reactions from the rest of the cell [23]. To exploit these benefits, scientists have begun cloning whole organelle genomes from various organisms including human, mouse, maize, rice, and some algae [24-29]. Yet, a rapid method for whole organelle genome engineering for eukaryotic algae has not been established.

The first hurdle to overcome is the need for a fast and inexpensive method for synthesizing, assembling, and storing synthetic organelle genomes. While processes for synthesizing and replacing chromosomes have been established for some prokaryotes [30-34] and eukaryotes [35], 
genome-scale engineering and delivery is still very challenging [36]. The large, repetitive elements and AT-rich sequences of organelle genomes complicate the synthesis and cloning processes. Spurious expression of cloned genomes can be toxic to host organisms including Saccharomyces cerevisiae and E. coli [37]. Importantly, the targeted delivery of whole organelle genomes to the appropriate cellular compartment in eukaryotic algal cells is still not possible.

Here, we report a rapid protocol for cloning the $P$. tricornutum mitochondrial genome and demonstrate its maintenance in eukaryotic and prokaryotic host strains as the first step of a platform for robust, genome-scale organelle engineering. We used transformation-associated recombination (TAR) cloning to capture the wild-type mitochondrial genome of $P$. tricornutum and developed a PCR-based approach to clone modified versions of the genome. We then demonstrated the maintenance of wild type and modified mitochondrial genomes in S. cerevisiae and E. coli.

\section{Material and Methods}

\subsection{Strains and Growth Conditions}

Phaeodactylum tricornutum (Culture Collection of Algae and Protozoa CCAP 1055/1) was grown in synthetic seawater (liquid L1 medium) without silica at $18^{\circ} \mathrm{C}$ under cool white fluorescent lights $\left(75 \mu \mathrm{E} \mathrm{m}^{-2} \mathrm{~s}^{-1}\right)$ and a photoperiod of $16 \mathrm{~h}$ light : $8 \mathrm{~h}$ dark. Liquid L1 media was made as previously described by [6]. Saccharomyces cerevisiae VL6-48 (ATCC MYA-3666: MAT $\alpha$ his3-

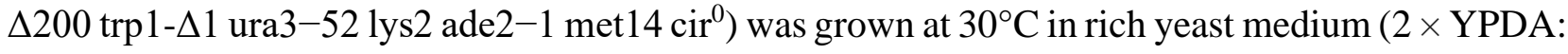
$20 \mathrm{~g}$ yeast extract, $40 \mathrm{~g}$ peptone, $40 \mathrm{~g}$ glucose, and $200 \mathrm{mg}$ adenine hemisulfate dihydrate), or synthetic complete medium lacking histidine, supplemented with adenine sulfate $\left(60 \mathrm{mg} \mathrm{L}^{-1}\right)$ (Teknova, Inc., Cat \#: C7112). Solid yeast media contained 2\% agar. After spheroplast transformation, all complete minimal media used contained $1 \mathrm{M}$ sorbitol [38]. Escherichia coli 
(Epi300, Lucigen, Cat \#: EC300110) was grown at $37^{\circ} \mathrm{C}$ in Luria Broth (LB) supplemented with chloramphenicol $\left(15 \mu \mathrm{g} \mathrm{mL} \mathrm{m}^{-1}\right)$.

\subsection{DNA Preparation}

\subsubsection{Isolation of $\boldsymbol{P}$. tricornutum DNA in agarose plugs}

For TAR-cloning, genomic DNA was isolated from $P$. tricornutum in agarose plugs. $P$. tricornutum $\left(1.0 \times 10^{7}\right.$ cells $\left.\mathrm{mL}^{-1}\right)$ was plated and grown on $1 \%$-agarose $\mathrm{L} 1$ plates for four days. Next, $1 \mathrm{~mL}$ of $1 \mathrm{M}$ sorbitol was used to scrape algal cells from each plate. Next, the combined cell suspension was centrifuged at $2000 \mathrm{rcf}$ for $2 \mathrm{~min}$ in $15 \mathrm{~mL}$ tube, followed by $3000 \mathrm{rcf}$ for $1 \mathrm{~min}$. Then, the supernatant was removed, and the cell pellet was resuspended in $2 \mathrm{~mL}$ of SPEM solution (1 M sorbitol, $10 \mathrm{mM}$ EDTA pH 7.5, $\mathrm{Na}_{2} \mathrm{HPO}_{4} \cdot 7 \mathrm{H}_{2} \mathrm{O}\left(2.08 \mathrm{~g} \mathrm{~L}^{-1}\right), \mathrm{NaH}_{2} \mathrm{PO}_{4} \cdot 1 \mathrm{H}_{2} \mathrm{O}\left(0.32 \mathrm{~g} \mathrm{~L}^{-1}\right)$ ) and incubated for 1 minute at $37^{\circ} \mathrm{C}$. The resuspended cells were then incubated for 5 min at $50^{\circ} \mathrm{C}$ and then mixed with an equal volume of $2.2 \%$ low-melting-point agarose in TAE buffer (40 mM Tris, $20 \mathrm{mM}$ acetic acid, and $1 \mathrm{mM}$ EDTA), which was also kept at $50^{\circ} \mathrm{C}$. Aliquots of $100 \mu \mathrm{L}$ were transferred into plug molds (BioRad, Cat \#:170-3713) and allowed to solidify for $10 \mathrm{~min}$ at $4^{\circ} \mathrm{C}$. To digest algal cell walls, the plugs were removed from the molds into 50-mL conical tubes containing $5 \mathrm{~mL}$ of protoplasting solution $((8.5 \mathrm{~mL}$ of SPEM solution, $500 \mu \mathrm{L}$ zymolyase-20 $\mathrm{T}$ solution $(50$ $\left.\mathrm{mg} \mathrm{mL} \mathrm{m}^{-1}\right), 500 \mu \mathrm{L}$ lysozyme $\left(25 \mathrm{mg} \mathrm{mL}^{-1}\right), 500 \mu \mathrm{L}$ hemicellulase $\left(25 \mathrm{mg} \mathrm{mL}^{-1}\right), 50 \mu \mathrm{L} \beta$ mercaptoethanol $(14.3 \mathrm{M})$ ) and incubated for $30 \mathrm{mins}$ at $37^{\circ} \mathrm{C}$. Next, the protoplasting solution was removed and the plugs were incubated with $5 \mathrm{~mL}$ of Proteinase $\mathrm{K}$ solution $(100 \mathrm{mM}$ EDTA (pH 8.0), $0.2 \%$ sodium deoxycholate, $1 \%$ sodium lauryl sarcosine, and $1 \mathrm{mg} \mathrm{mL}^{-1}$ Proteinase $\mathrm{K}$ ) for 24 $\mathrm{h}$ at $50^{\circ} \mathrm{C}$. Then, the plugs were washed four times as follows: twice with $25 \mathrm{~mL}$ of wash buffer $(20$ 
$\mathrm{mM}$ Tris and $50 \mathrm{mM}$ EDTA, $\mathrm{pH} 8.0$ ) for $2 \mathrm{~h}$ each at room temperature (RT), once with $25 \mathrm{~mL}$ of wash buffer containing $1 \mathrm{mM}$ PMSF for $2 \mathrm{~h}$ at RT, and a final wash with $25 \mathrm{~mL}$ of wash buffer for $2 \mathrm{~h}$.

For restriction digestion, the plugs were placed in 1.5-mL microcentrifuge tubes and washed additionally with $1 \mathrm{~mL}$ of $0.1 \mathrm{X}$ wash buffer for $1 \mathrm{~h}$ at $\mathrm{RT}$, followed by a 5 -h wash in $1 \mathrm{X}$ restriction buffer at RT. Finally, each plug was incubated with 50 units $\mathrm{mL}^{-1}$ of restriction enzyme in $1 \mathrm{~mL}$ of restriction buffer for $4 \mathrm{~h}$ at $37^{\circ} \mathrm{C}$. Following the digest, the plugs were washed for $1 \mathrm{~h}$ in $1 \mathrm{~mL}$ of TE buffer ( $\mathrm{pH} 8$ ). Next, the TE buffer was removed and a fresh $100 \mu \mathrm{L}$ of TE buffer (pH 8) was added, and plugs were melted for $10 \mathrm{~min}$ at $65^{\circ} \mathrm{C}$. The solution was then equilibrated to $42^{\circ} \mathrm{C}$ for 10 min before adding $2 \mu \mathrm{L}$ of $\beta$-agarase (NEB). Finally, the solution was incubated at $42^{\circ} \mathrm{C}$ for $1 \mathrm{~h}$ to allow the agarose to be digest. On average, each plug yielded a DNA concentration of $300 \mathrm{ng} \mu \mathrm{L}^{-1}$.

\subsubsection{DNA isolation by modified alkaline lysis}

DNA from E. coli, yeast, and algae was isolated as described by [16]. Before isolating plasmid DNA from E. coli for diagnostic restriction digests or sequencing, cells were induced with arabinose. For this plasmid induction, E. coli overnight cultures were diluted 1:50 into $50 \mathrm{~mL}$ of LB media supplemented with chloramphenicol $(15 \mu \mathrm{g} \mathrm{mL}-1)$ and arabinose $(100 \mu \mathrm{g} \mathrm{mL}-1)$ and grown for $8 \mathrm{~h}$ at $37^{\circ} \mathrm{C}$.

\subsection{DNA preparation for PCR cloning}

PCR amplification of mitochondrial fragments was performed using $P$. tricornutum genomic DNA (first iteration) or mitochondrial DNA isolated from E. coli as described in Methods 2.2.2 
(second iteration) as template DNA. The mitochondrial genome was amplified as eight overlapping fragments (primers: BK 141-144F/R, 145F/250R, 247F/146R, 147F/R, and 148F/140R, listed in Supplementary Table 1), as well as two additional fragments (primers: BK 88F/245R and 251F/88R, listed in Supplementary Table 1) to amplify the pAGE3.0 plasmid [17].

Each fragment was individually amplified in a $25-\mu \mathrm{L}$ PCR reaction using $1 \mu \mathrm{L}$ of PrimeSTAR GXL polymerase (Takara Bio Inc., \#R050A), $1 \mu \mathrm{L}$ of template DNA (10-100 ng $\mu \mathrm{L}^{-1}$ genomic DNA or plasmid DNA isolated from E. coli), and the respective forward and reverse primers each at a final concentration of $0.2 \mu \mathrm{M}$. The thermocycler was programmed as follows: five cycles of $98^{\circ} \mathrm{C}$ for 10 seconds, $50^{\circ} \mathrm{C}$ for 15 seconds, and $68^{\circ} \mathrm{C}$ for 480 seconds, followed by 25 cycles of $98^{\circ} \mathrm{C}$ for 10 seconds, $55^{\circ} \mathrm{C}$ for 15 seconds, and $68^{\circ} \mathrm{C}$ for 480 seconds, and one cycle of $68^{\circ} \mathrm{C}$ for 600 seconds, finishing with an infinite hold at $12^{\circ} \mathrm{C}$. PCR product amplification was confirmed by performing agarose gel electrophoresis with $2 \mu \mathrm{L}$ of PCR product on a $1.4 \%$ agarose $(w / v)$ gel.

To eliminate plasmid template DNA, PCR products were treated with 10 units $(0.5 \mu \mathrm{L})$ of DpnI restriction endonuclease (New England Biolabs Ltd., \#R0176), incubated at $37^{\circ} \mathrm{C}$ for 30 minutes, and deactivated for 20 minutes at $80^{\circ} \mathrm{C}$. Fragments were then purified using the EZ-10 Spin Column PCR Products Purification Kit (BioBasic Inc., \#BS363) and were combined into a single $1.5-\mathrm{mL}$ microcentrifuge tube to equimolar concentrations (approximately $200 \mathrm{ng}$ of each fragment) and a total volume of $\sim 30 \mu \mathrm{L}$.

\subsection{DNA fragment preparation for transformation-associated recombination (TAR) cloning}

P. tricornutum genomic DNA was digested with PvuI restriction enzyme, as described in section 2.2.1. The pAGE3.0 plasmid was amplified as two fragments (primers: BK 88F/93R \& 92F/88R, listed in Supplementary Table 1). Each fragment was individually amplified in a $20 \mu \mathrm{L}$ 
PCR reaction using $0.8 \mu \mathrm{L}$ PrimeSTAR GXL polymerase (Takara Bio Inc., \#R050A), $0.8 \mu \mathrm{L}$ of template DNA (10 ng $\mu \mathrm{L}^{-1}$ of plasmid template DNA isolated from E. coli), and the respective forward and reverse primers at a final concentration of $0.2 \mu \mathrm{M}$. The thermocycler conditions used were as follows: 30 cycles of $98^{\circ} \mathrm{C}$ for 10 seconds, $62^{\circ} \mathrm{C}$ for 15 seconds, and $68^{\circ} \mathrm{C}$ for 150 seconds, one cycle of $68^{\circ} \mathrm{C}$ for 600 seconds, and an infinite hold at $12^{\circ} \mathrm{C}$. PCR product amplification was confirmed by performing agarose gel electrophoresis with $1 \mu \mathrm{L}$ of PCR product on a $1.4 \%$ agarose $(w / v)$ gel.

To eliminate the template plasmid DNA from the PCR products, DpnI treatment, and purification was performed as described above. Then combined into a single 1.5-mL microcentrifuge tube the fragments were added in the following proportions: $10 \mu \mathrm{L}$ linearize genome $\left(\sim 300 \mathrm{ng} \mu \mathrm{L}^{-1}\right)$, and $7 \mu \mathrm{L}$ for each plasmid backbone fragment $\left(\sim 300-500 \mathrm{ng} \mu \mathrm{L}^{-1}\right)$ prior to yeast transformation.

\subsection{Yeast Spheroplast Transformation Protocol}

Yeast spheroplasts were prepared as described by [38], with the exception that mixtures of DNA fragments replaced the bacterial culture. After yeast transformation, 300 and $700 \mu \mathrm{L}$ of yeast cell suspension were each added to a $15-\mathrm{mL}$ Falcon tube containing $8 \mathrm{~mL}$ of melted $2 \%$-agar yeast media lacking histidine supplemented with adenine sulfate and sorbitol, which had been kept at $50^{\circ} \mathrm{C}$ in a $15 \mathrm{~mL}$ Falcon tube. After $4-6$ gentle inversions, the mixture was poured on top of an agar plate containing $10 \mathrm{~mL}$ of yeast media lacking histidine supplemented with adenine sulfate and sorbitol and containing $2 \%$ agar. The plate was then incubated at $30^{\circ} \mathrm{C}$ for $3-5$ days until colonies emerged for screening. 


\subsection{E. coli Transformation}

TransforMax Epi300 electrocompetent E. coli cells (Lucigen, Cat \#: EC300110) were thawed on ice for 20 mins. Then, $20-\mu \mathrm{L}$ aliquots of $E$. coli cells were transferred to sterile $1.5-\mathrm{mL}$ microcentrifuge tubes and mixed with $1 \mu \mathrm{L}$ of total DNA extracted from a single yeast colony. A Gene Pulser Xcell Electroporation System (BioRad) was set to $25-\mu$ F capacitance, $200-\Omega$ resistance, and $2.5-\mathrm{kV}$ voltage. The mixture of DNA and E. coli was then transferred to an ice-cold 2-mm electrocuvette and electroporated. Immediately, $1 \mathrm{~mL}$ of SOC media was added to the electrocuvette, which was then incubated at $37^{\circ} \mathrm{C}$ for $30 \mathrm{mins}$, without shaking. Next, the mixture was transferred to a sterile $1.5-\mathrm{mL}$ microcentrifuge tube and incubated for $1 \mathrm{~h}$ at $37^{\circ} \mathrm{C}$, shaking at $225 \mathrm{rpm}$. Finally, $100 \mu \mathrm{L}$ of transformed cells were plated on selective LB media supplemented with chloramphenicol $(15 \mu \mathrm{g} \mathrm{mL}-1)$ and incubated overnight at $37^{\circ} \mathrm{C}$.

\subsection{Screening Strategy}

\subsubsection{Screening yeast colonies}

To identify positive clones generated using the PCR and TAR cloning methods, all individual yeast colonies were struck onto selective $2 \%$-agar plates lacking histidine supplemented with adenine sulfate, and grown overnight at $30^{\circ} \mathrm{C}$. Next, each streak was passed onto a second selective $2 \%$ agar plate and again grown overnight at $30^{\circ} \mathrm{C}$. For TAR-cloning, approximately 10 yeast colonies were pooled (20 pools in total) by picking up a small amount of each colony and resuspending them together in $100 \mu \mathrm{L}$ of TE buffer. For PCR-based cloning, the same protocol was followed except that cells from 20 individual colonies were used for each reaction. Subsequently, 
for both TAR-cloning and PCR-based cloning methods, the resuspended cells were incubated at $95^{\circ} \mathrm{C}$ for 15 mins. The tubes were then centrifuged for approximately 30 seconds using a mini centrifuge (Scilogex, D1008). Next, $1 \mu \mathrm{L}$ of the supernatant was used as the DNA template for diagnostic Multiplex (MPX) PCR.

MPX primer pairs were designed to have an optimized melting temperature of $60^{\circ} \mathrm{C}$ using the online tool Primer3 (http://bioinfo.ut.ee/primer3-0.4.0/). The MPX PCR was performed according to the Qiagen Multiplex PCR Handbook. To test potential pPT-TAR and pPT-PCR clones, two sets of MPX PCR were run, each yielding three amplicons. The first primer set, BK901, 904, and 906 F/R, was used to generate amplicons of 265-, 334-, and 507-bp sizes, respectively. The second primer set, BK 902, 903, and 905 F/R, were used to generate 171-, 224-, and 405-bp amplicons, respectively. $2 \mu \mathrm{L}$ of the reaction products were loaded onto a $2 \%$ agarose gel for electrophoresis and then analyzed. Next, DNA was isolated (as described in 2.2.2) from selected positive clones and transformed into E. coli (as described in 2.6).

\subsubsection{Screening $E$. coli colonies}

First, one to eight $E$. coli colonies transformed with DNA from positive yeast clones were screened using the same MPX PCR method as described above for yeast colonies.

Next, the selected positive colonies were screened by diagnostic digestion. To perform diagnostic digestion, DNA was isolated from E. coli as described in section Methods 2.2.2 (plasmids were induced with arabinose), and then the concentration of total isolated DNA was obtained using the DeNovix Inc. DS-11 FX+ Spectrophotometer. DNA preparations were approximately $5000 \mathrm{ng}$ $\mu \mathrm{L}^{-1}$ before digestion. Digestion reactions were generated using $5 \mathrm{uL}$ of DNA, $2 \mu \mathrm{L}$ of $3.1 \mathrm{NEB}$ buffer (Cat \#: B7203S), 0.2 $\mu$ L of SrfI (Cat \#: R0629L), 0.2 $\mu \mathrm{L}$ of SacII (Cat \#: R0157L), and 12.6 
$\mu \mathrm{L}$ water. Reaction mixtures were incubated at $37^{\circ} \mathrm{C}$ for 60 minutes and then $1 \mu \mathrm{L}$ was loaded onto a $1 \%$ agarose gel for electrophoresis.

For further confirmation, the isolated plasmid DNA was submitted to the CCIB DNA Core at Massachusetts General Hospital for whole plasmid sequencing and reference mapping. Sequences obtained were aligned with their respective references using the algorithm built into Geneious version 2020.0, created by Biomatters. Alignment disagreements were identified as mutations, and each mutation was individually analyzed to curate a list of mutations (Supplemental Table 2).

\subsection{Evaluation of growth phenotypes of host strains}

\subsubsection{E. coli growth in liquid media}

E. coli Epi300 strains harbouring pPT-PCR C1 and C2, pPT-TAR C1 and C2, and pAGE3.0 and pPtGE31 control plasmids (lacking mitochondrial genome), were inoculated and grown overnight in $5 \mathrm{~mL}$ of $\mathrm{LB}$ media supplemented with $15 \mu \mathrm{g} \mathrm{mL}-1$ chloramphenicol at $37^{\circ} \mathrm{C}$ with shaking at $225 \mathrm{rpm}$. The saturated cultures were diluted 100-fold into $5 \mathrm{~mL}$ of the same media and grown for $2 \mathrm{~h}$ in 50-mL conical Falcon tubes under the same conditions. The cultures were placed on ice and diluted to an $\mathrm{OD}_{600}$ of 0.1 in $\mathrm{LB}$ media supplemented with $15 \mu \mathrm{g} \mathrm{mL}^{-1}$ chloramphenicol (uninduced) or LB media supplemented with $15 \mu \mathrm{g} \mathrm{mL}-1$ chloramphenicol and $100 \mathrm{ug} \mathrm{mL}^{-1}$ arabinose (induced). In quadruplicate, $200 \mu \mathrm{L}$ of each uninduced and induced culture was aliquoted into a 96-well plate. Once loaded, the 96-well plate was incubated in a 96-well plate reader, Epoch 2 (BioTek). While in the plate reader, the strains were incubated at $37^{\circ} \mathrm{C}$ with continuous, doubleorbital shaking. $\mathrm{OD}_{600}$ measurements were taken every 15 mins for $5 \mathrm{~h}$, for a total of 20 readings using Gen5 data analysis software version 3.08 (BioTek). This experiment was performed twice, 
therefore for each strain, eight measurements were obtained and averaged, and the standard deviation of the mean was calculated. The doubling time (td) of each strain was determined.

\subsubsection{S. cerevisiae growth in liquid media}

S. cerevisiae VL6-48 strains harbouring pPT-PCR C1 and C2, pPT-TAR C1 and C2, and pAGE3.0 and pPtGE31 control plasmids (lacking mitochondrial genome), were inoculated and grown overnight in $5 \mathrm{~mL}$ of synthetic complete yeast medium lacking histidine at $30^{\circ} \mathrm{C}$ with shaking at $225 \mathrm{rpm}$. The saturated cultures were diluted 100 -fold into $5 \mathrm{~mL}$ of the same media and allowed to grow for $2 \mathrm{~h}$ in a $50 \mathrm{~mL}$ conical Falcon tube under the same conditions. The cultures were diluted to an $\mathrm{OD}_{600}$ of 0.1 in the same media, and $200 \mu \mathrm{L}$ of each culture was aliquoted into a 96 -well plate, in quadruplicate. Once loaded, the 96-well plate was incubated in a 96-well plate reader, Epoch 2 (BioTek). While in the plate reader, the strains were incubated at $30^{\circ} \mathrm{C}$ with continuous shaking. $\mathrm{OD}_{600}$ measurements were taken every 15 mins for $12 \mathrm{~h}$ for a total of 49 readings using Gen5 data analysis software version 3.08 (BioTek). For each strain, four measurements were obtained and averaged, and the standard deviation of the mean was calculated. The doubling time (Td) of each strain was determined.

\subsubsection{E. coli and $S$. cerevisiae growth on solid media}

E. coli and S. cerevisiae strains harbouring pPT-PCR C1 and C2, pPT-TAR C1 and C2, and pAGE3.0 and pPtGE31 control plasmids (lacking mitochondrial genome), were inoculated and grown overnight in LB media supplemented with $15 \mu \mathrm{g} \mathrm{mL} \mathrm{m}^{-1}$ chloramphenicol at $37^{\circ} \mathrm{C}$, and synthetic complete yeast medium lacking histidine at $30^{\circ} \mathrm{C}$, respectively. The saturated cultures were diluted 
100-fold in their corresponding media and grown for $2 \mathrm{~h}$. The cultures were diluted to an $\mathrm{OD}_{600}$ of 0.1 , which was used to generate a range of dilutions for E. coli and S. cerevisiae. The dilution series were plated using $5 \mu \mathrm{L}$ aliquots onto their corresponding selection plates: $1.5 \%$ agar LB plates supplemented with $15 \mu \mathrm{g} \mathrm{mL} \mathrm{m}^{-1}$ chloramphenicol (uninduced) or with $15 \mu \mathrm{g} \mathrm{mL} \mathrm{m}^{-1}$ chloramphenicol and arabinose (induced) for $E$. coli, and $2 \%$ agar synthetic complete yeast medium plates lacking histidine for S. cerevisiae. Dilution plates for E. coli strains were grown overnight at $37^{\circ} \mathrm{C}$, and dilution plates for $S$. cerevisiae strains were grown for two days at $30^{\circ} \mathrm{C}$.

\section{Results and Discussion}

3.1. Design-Build-Test cycle to enable rapid engineering of organelle genomes

Currently, there are no established methods for replacing whole eukaryotic algal organelle genomes. To address this need and enable full use of the organelle compartment for installing synthetic genomes, we are developing a design-build-test cycle for efficient capture, manipulation, delivery, and installation of organelle genomes (Figure 1A).

In one iteration of the design and build stages of the cycle, we cloned a whole mitochondrial genome and a reduced version with a repetitive region removed. To capture the whole mitochondrial genome, transformation-associated recombination (TAR) cloning was used (Figure 1B). For TAR cloning, total genomic DNA was prepared in agarose plugs to obtain isolated, intact organelle genomes. Next, the mitochondrial DNA was linearized by a restriction enzyme that recognizes a single cut site in the targeted organelle genome. If there are no unique restriction enzyme cut-sites available, it is possible to select a restriction enzyme that cuts in multiple locations and perform a partial digest to obtain a proportion of genomes with a single cut at the desired location. If the cut- 
site resides within an essential gene, a recoded version (to remove the restriction site) of the gene can be added to the plasmid backbone. Alternatively, once the genome is cloned in yeast, the plasmid backbone can be moved to a different location by co-transformation of a plasmid containing homology hooks to the new location and another fragment that will delete the plasmid in the original location and restore the interrupted gene. Finally, a CRISPR/Cas9 system can be devised to produce appropriate cut-sites at the desired location $[39,40]$.

A)

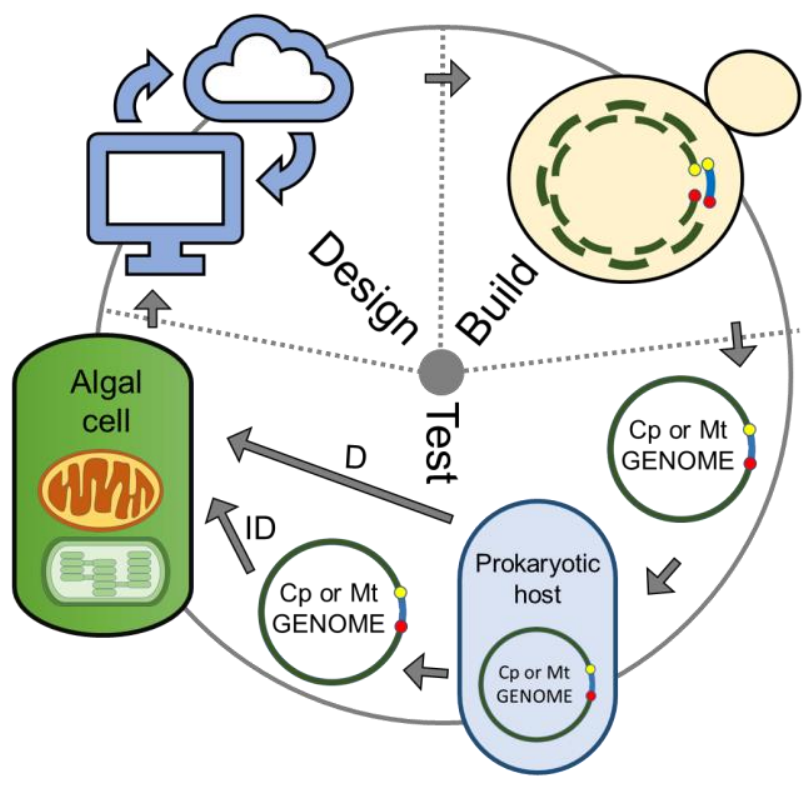

B)

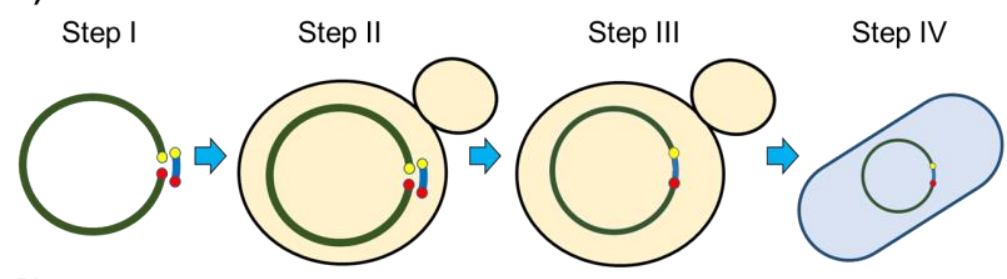

C)

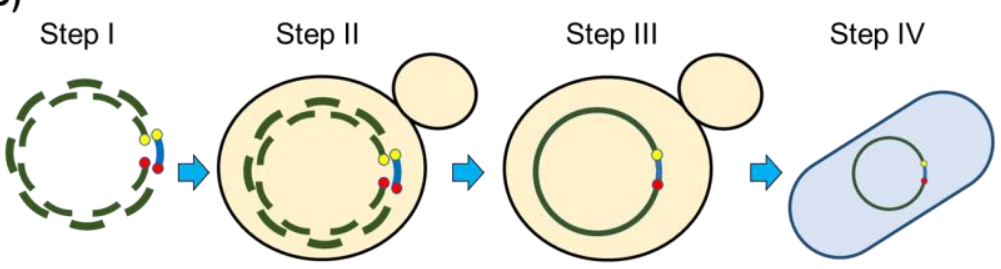

Figure 1. Design-Build-Test cycle for the rapid engineering of organelle genomes. A) Genomes will be designed based on existing knowledge and discoveries from previous cycles; in the build stage, genomes will be synthesized, then assembled and cloned in yeast; in the test stage, genomes 
will be isolated from yeast, moved to an intermediate prokaryotic host and delivered directly (D) (e.g. conjugation, cell fusion) or indirectly (ID) (e.g. electroporation, biolistic-mediated transformation) to the destination organelle compartment to test for viability, function, and localization. B-C) Schematic of the approaches used to clone the mitochondrial genomes of $P$. tricornutum. B) TAR cloning method; C) PCR-based cloning method. Step I differs between the PCR and TAR cloning methods where, for the PCR method, multiple overlapping fragments (green) are amplified, while for the TAR cloning method, genomic DNA is linearized at a specific location. For both methods, the plasmid backbone (blue) contains homology overlaps to the appropriate fragments or location in the genome. Steps II-IV are the same for both methods including DNA transformation (Step II) and assembly in S. cerevisiae via homologous recombination (Step III), and transfer of clone genomes into E. coli (Step IV).

The linearized algal mitochondria genome was captured by transforming it into $S$. cerevisiae along with a PCR-amplified plasmid backbone containing homology on each end to the organellar regions flanking the cut-site. Although the process is more time-consuming, an entire organellar genome can be cloned. In PCR-based cloning (Figure 1C), the mitochondrial genome was cloned indirectly by amplifying fragments from total genomic DNA with homologous DNA overhangs, followed by transformation into $S$. cerevisiae with the plasmid backbone. This process has been shown to allow for fast assembly of large plasmids [41] but it also has some drawbacks including the risk of introducing unwanted point mutations and difficulty amplifying larger repetitive elements, which could limit the practicality and versatility of this approach. In both methods, elements required for replication in yeast (e.g. CEN6-ARSH4-HIS3) and E. coli (e.g. the origin of replication, and selectable marker), must be provided as one or multiple plasmid backbone fragments containing appropriate homologous overhangs. 
3.2. Cloning of the $P$. tricornutum mitochondrial genome

Using the PCR-based approach, we cloned a reduced version of the P. tricornutum mitochondrial genome (Figure 2A). The wild-type genome was PCR-amplified in eight overlapping fragments that excluded a $35 \mathrm{kbp}$ region of direct repeats [9]. In place of this repeat region, two fragments with genetic elements required for replication and selection in S. cerevisiae, E. coli, and algae (nuclear localization) were amplified from the multi-host shuttle plasmid pAGE3.0 [17]. In total, 10 DNA fragments were amplified (Figure 2B) and assembled following transformation and homologous recombination in S. cerevisiae spheroplasts, yielding 5023 transformed yeast colonies (Table 1). After moving the assembled plasmids to E. coli, two clones, pPT-PCR C1 and C2, that were validated by multiplex (MPX) PCR and restriction digests (Figure 2C-D) were sequenced and analyzed for mutations (Section 3.3).

Importantly, we wanted to assess the fidelity of the PCR-based cloning method by comparing cloned sequences to their parental reference. However, the amplified fragments initially used in this iteration were derived from a heterogenic population of mitochondrial genomes, which may differ from the published sequence. Therefore, to directly determine the mutation rate of the cloning method, the mitochondrial genome was re-amplified using DNA isolated from an isogenic culture of E. coli carrying pPT-PCR C2. The 10 fragments were assembled using the same method, with similar results as the first assembly (Table 1, Section 3.3). Two additional clones, pPT-PCR C2-1 and C2-2, were selected for further analysis.

To clone the complete, repeat-containing genome, we used the TAR-based approach (Figure 2A). Total $P$. tricornutum genomic DNA was digested with the restriction enzyme PvuI, which cuts the mitochondrial genome at a single site. We amplified the plasmid backbone from pAGE3.0 as 
two fragments with end homology to each other and the genomic sequences flanking the PvuI cut site. Transforming both PCR-amplified plasmid backbone fragments and the linearized genome into S. cerevisiae spheroplasts yielded 204 colonies (Table 1) from which two clones, pPT-TAR C1 and C2, were identified as positive for the presence of the mitochondrial genome using MPX PCR. We then transferred these genomes to E. coli and analyzed again with MPX PCR and performed a diagnostic restriction digest (Figure 2C-D). Although the build stage using the TAR-cloning approach was successful, it was time-consuming and labor-intensive due to the requirement of obtaining high-quality DNA and screening a larger number of colonies. Nonetheless, this iteration can act as a good template for future design-build cycles, particularly for cloning large organellar genomes that are difficult to PCR-amplify.

Table 1. Cloning of the P. tricornutum mitochondrial genome in the host organisms $S$. cerevisiae and E. coli. Two PCR-cloning assemblies and one TAR-cloning assembly were performed. For the E. coli selection media, CM indicates chloramphenicol antibiotic.

\begin{tabular}{|c|c|c|c|c|c|c|c|}
\hline \multirow{2}{*}{$\begin{array}{c}\text { Design } \\
\text { Assembly Type } \\
\text { DNA Source }\end{array}$} & \multicolumn{3}{|c|}{ S. cerevisiae } & \multicolumn{4}{|c|}{ E. coli } \\
\hline & $\begin{array}{l}\text { Selection } \\
\text { Media }\end{array}$ & $\begin{array}{l}\text { Colony } \\
\text { Count }\end{array}$ & $\begin{array}{c}\text { MPX PCR } \\
\text { Screen } \\
\text { Positive/Total } \\
\end{array}$ & $\begin{array}{c}\text { Selection } \\
\text { Media }\end{array}$ & $\begin{array}{l}\text { Selected Yeast } \\
\text { Colony: } E \text {. coli } \\
\text { Colony Count } \\
\end{array}$ & $\begin{array}{c}\text { MPX PCR } \\
\text { Screen } \\
\text { Positive/Total } \\
\end{array}$ & $\begin{array}{c}\text { Final Genomes } \\
\text { Selected For } \\
\text { Analysis } \\
\end{array}$ \\
\hline $\begin{array}{l}\text { Reduced Genome } \\
\text { PCR - } 10 \text { Fragments } \\
\text { Genomic DNA }\end{array}$ & -Histidine & 5023 & $20 / 20$ & $\mathrm{CM}$ & $\begin{array}{l}\text { Yeast colony } \mathrm{C} 1: 30 \\
\text { Yeast colony } \mathrm{C} 2: 18\end{array}$ & $\begin{array}{l}\mathrm{C} 1=8 / 8 \\
\mathrm{C} 2=8 / 8\end{array}$ & $\begin{array}{l}\text { pPT-PCR C1 } \\
\text { pPT-PCR C2 }\end{array}$ \\
\hline $\begin{array}{l}\text { Reduced Genome } \\
\text { PCR - } 10 \text { Fragments } \\
\text { Clone pPT-PCR C2 }\end{array}$ & -Histidine & 4880 & $20 / 20$ & $\mathrm{CM}$ & N/D & $\begin{array}{l}\mathrm{C} 2-1=5 / 5 \\
\mathrm{C} 2-2=5 / 5\end{array}$ & $\begin{array}{l}\text { pPT-PCR C2-1 } \\
\text { pPT-PCR C2-2 }\end{array}$ \\
\hline $\begin{array}{c}\text { Full Genome } \\
\text { TAR - } 3 \text { Fragments } \\
\text { Digested Genomic DNA }\end{array}$ & -Histidine & 604 & $2 / 204$ & $\mathrm{CM}$ & $\begin{array}{l}\text { Yeast colony } \mathrm{C} 1: 119 \\
\text { Yeast colonyC2: } 46\end{array}$ & $\begin{array}{l}\mathrm{C} 1=1 / 1 \\
\mathrm{C} 2=2 / 2\end{array}$ & $\begin{array}{l}\text { pPT-TAR C1 } \\
\text { pPT-TAR C2 }\end{array}$ \\
\hline
\end{tabular}


A)
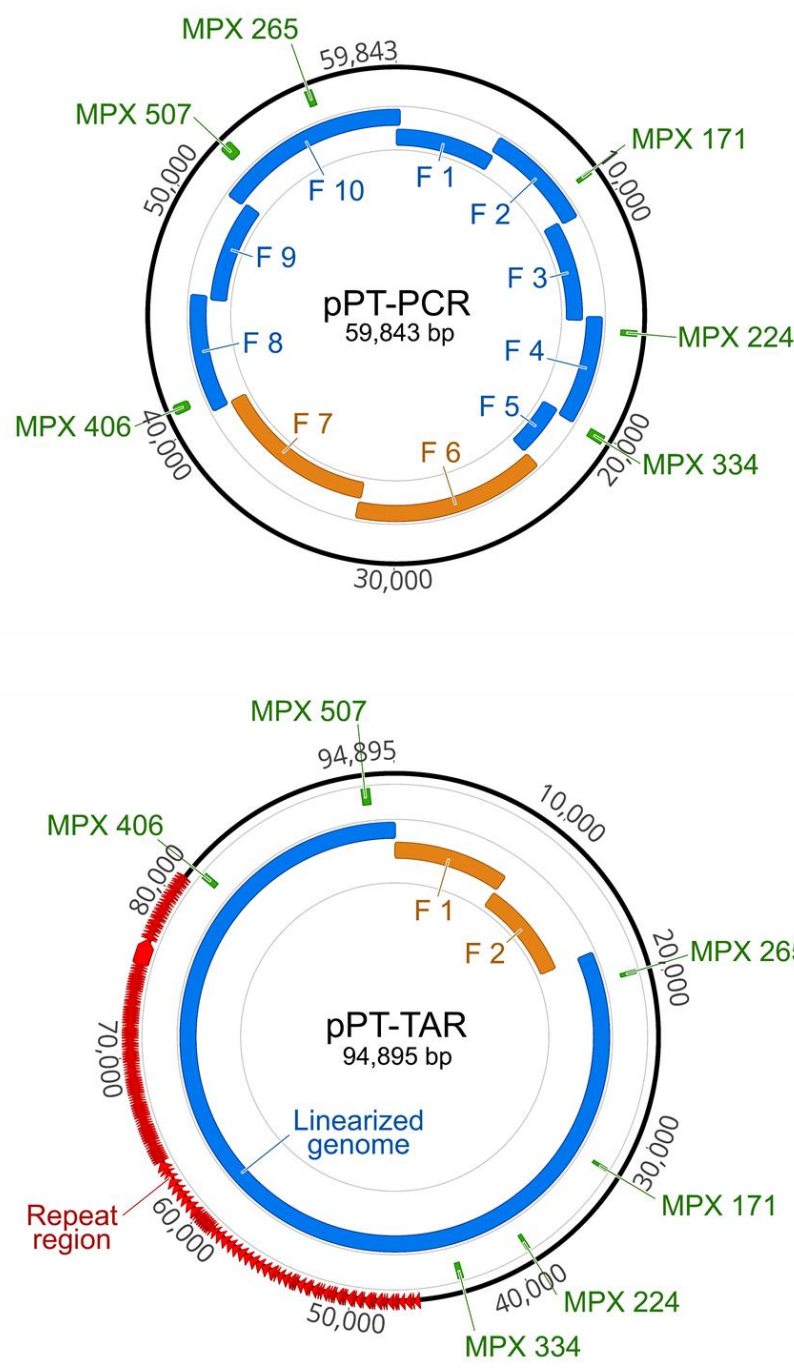

B)

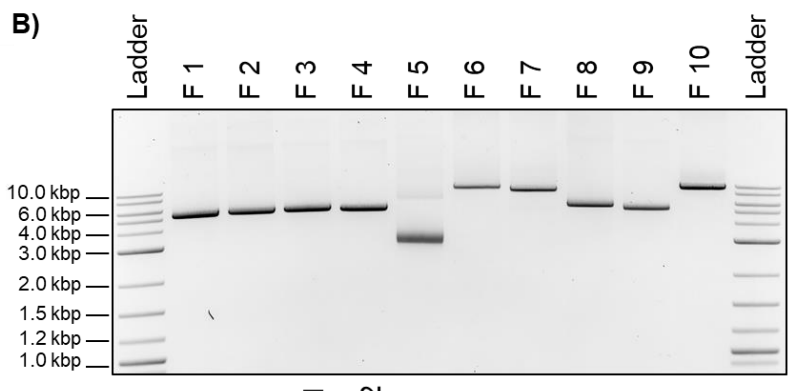

C)

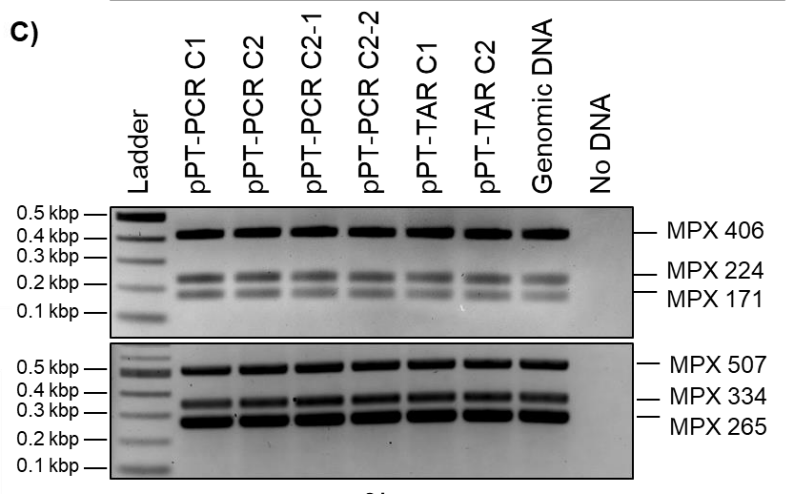

D)
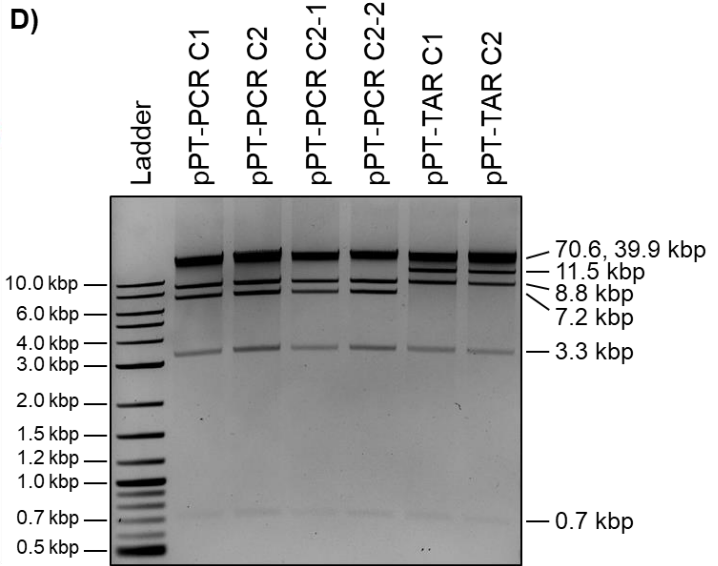

Figure 2. Design, amplification, and analyses of cloned P. tricornutum mitochondrial genomes. A)

Plasmid maps of P. tricornutum's mitochondrial genomes cloned using PCR (top) or TAR (bottom) methods. For the PCR-based cloning method, the relative sizes and positions of the eight mitochondrial fragments (blue), and the two plasmid backbone fragments (orange) are shown. For the TAR-based cloning method, the relative sizes and positions of the linearized genome (blue) and the two plasmid backbone fragments (orange) are shown. In addition, the six MPX PCR amplicons used for diagnostic screening are indicated (green). These images were generated using Geneious version 2020.0, created by Biomatters. B) Agarose gel electrophoresis of the 10 PCR amplified 
fragments of the P. tricornutum mitochondrial genome for PCR-based cloning including the pAGE3.0 backbone (Fragments 6 and 7). The resulting amplicon sizes for Fragments 1 to 10 are 5217, 5190, 5197, 5175, 2765, 9124, 8571, 5605, 5299, and 9264 bp, respectively. C) MPX PCR screen of six cloned algal mitochondrial genomes isolated from E. coli. The expected size for each MPX amplicon is indicated by its name (in bp). D) Diagnostic restriction digest of six cloned algal mitochondrial genomes using SrfI and SacII. For the pPT-PCR clones, the expected band sizes are 39925, 8758, 7177, 3276, and $707 \mathrm{bp}$; and for the pPT-TAR clones, the expected band sizes are 70647, 11506, 8758, 3276, and 707 bp. Notes: 1) We did not see a size difference between the 70.6kbp and 39.9-kbp fragments, which is most likely due to the electrophoresis conditions (1\% agarose gel, $100 \mathrm{~V}$ for 90 minutes); 2) The 707-bp band is present but very faint. For all gels, we used NEB 2-log ladder.

3.3 Sequence analysis of cloned $P$. tricornutum mitochondrial genomes

The six selected $P$. tricornutum mitochondrial clones were sequenced and analyzed for mutations. Sequences obtained for the original PCR-cloned (pPT-PCR C1 and pPT-PCR C2) and TAR-cloned (pPT-TAR C1 and pPT-TAR C2) plasmids were aligned to reference sequences based on the published sequence from Oudot-Le Secq and Green (2011) and the plasmid from Brumwell et al. (2019); and the reassembled PCR-cloned plasmids (pPT-PCR C2-1 and pPT-PCR C2-2) were aligned to the sequence of their parent clone, pPT-PCR C2. Upon analyzing mutations in pPT-PCR $\mathrm{C} 1$ and $\mathrm{C} 2$, an average of 7 mutations per $60 \mathrm{kbp}$ was found (Table 2), which corresponds to 1 mutation per $8.6 \mathrm{kbp}$. The two reassembled clones, pPT-PCR C2-1 and C2-2, acquired an average of 3 mutations per $60 \mathrm{kbp}$ (Table 2), corresponding to 1 mutation per $20 \mathrm{kbp}$. See Supplementary Table 2 for additional information about specific mutations. pPT-TAR C1 had only a single 
synonymous substitution (Table 2). However, the other clone generated using this method, pPTTAR C2, contained a series of deletions in the repetitive region of the P. tricornutum mitochondrial genome (Table 2). This clone also carried seven base-pair substitutions and an insertion of 43 bps, albeit all in noncoding regions of the plasmid. The difference in mutation rate between these two plasmids could be the result of recombination of the highly repetitive region of the mitochondrial genome during TAR cloning, or an artifact of the sequencing method used as resolving repetitive regions may require the use of long-read sequencing technologies.

Genetic changes found using both cloning methods could have occurred during the cloning process of each mitochondrial plasmid or during propagation in the host organisms harboring the plasmids. It is also plausible that some of these variants could naturally exist in the heterogeneous population of $P$. tricornutum mitochondrial genomes. If desired, identified mutations could be fixed through additional iterations of the design-build-test cycle.

Table 2. Summary of mutations identified in the cloned $P$. tricornutum mitochondrial plasmids. Identified mutations are categorized as point mutations (synonymous, missense, nonsense, and those found in non-coding regions) or gap mutations (insertions and deletions, either noncoding or resulting in frameshifts).

\begin{tabular}{|c|c|c|c|c|c|c|c|c|c|}
\hline \multirow{3}{*}{ Clone } & \multicolumn{4}{|c|}{ Point Mutations } & \multicolumn{4}{|c|}{ Gap Mutations } & \multirow{3}{*}{ Tota } \\
\hline & \multirow{2}{*}{$\begin{array}{l}\text { Synon- } \\
\text { ymous }\end{array}$} & \multirow{2}{*}{ Missense } & \multirow{2}{*}{ Nonsense } & \multirow{2}{*}{$\begin{array}{l}\text { Non- } \\
\text { coding }\end{array}$} & \multicolumn{2}{|c|}{ Noncoding } & \multicolumn{2}{|c|}{ Deletions } & \\
\hline & & & & & Insertions & Deletions & Insertions & Deletions & \\
\hline pPT-PCR C1 & 0 & 4 & 0 & 2 & 1 & 1 & 1 & 0 & 9 \\
\hline pPT-PCR C2 & 0 & 3 & 1 & 0 & 0 & 1 & 0 & 0 & 5 \\
\hline pPT-PCR C2-1 & 0 & 3 & 0 & 2 & 0 & 0 & 0 & 0 & 5 \\
\hline pPT-PCR C2-2 & 0 & 1 & 0 & 0 & 0 & 0 & 0 & 0 & 1 \\
\hline pPT-TAR C1 & 1 & 0 & 0 & 0 & 0 & 0 & 0 & 0 & 1 \\
\hline pPT-TAR C2 & 0 & 0 & 0 & 7 & 1 & 8 & 0 & 0 & 19 \\
\hline
\end{tabular}

3.4 Maintenance of $P$. tricornutum's mitochondrial plasmids in host organisms 
S. cerevisiae and E. coli were used as host organisms to capture and store P. tricornutum's mitochondrial genome. S. cerevisiae was chosen because it is currently the best organism for assembling large DNA molecules due to its highly efficient homologous recombination machinery and demonstrated ability to maintain a wide range of genomes without adverse effects [42]. However, when using standard protocols for isolating plasmid DNA, the yields from S. cerevisiae tend to be low. To overcome this problem, after assembly in S. cerevisiae, the cloned mitochondrial plasmids were transformed into E. coli. In E. coli, the mitochondrial plasmids, which contain an arabinose-inducible origin of replication, can be induced to a higher copy number to generate increased DNA yields. Importantly, propagating genomes in E. coli allows for the development of direct transfer methods, such as conjugation, to deliver the plasmids to the desired destination organism. At the same time, because mitochondrial genomes are of prokaryotic origin, there is a chance that a prokaryotic host would express functional proteins that might have adverse or toxic effects.

We sought to examine the burden of propagating the cloned mitochondrial genomes in eukaryotic and prokaryotic host strains. Colony formation on selective plates and growth rates in liquid media for both $S$. cerevisiae and E. coli strains carrying these plasmids were evaluated. If a plasmid causes cellular stress, it can decrease the growth rate and result in the formation of smaller or fewer colonies on the plate. In S. cerevisiae, there was no observable decrease in colony size when strains harbouring cloned genomes were spot plated, as compared with control plasmids that have the same backbone, pAGE3.0 and pPtGE31 ${ }^{6}$ (Figure 3A). Next, we compared growth in liquid media by using a 96-well plate reader. Interestingly, the strains carrying the mitochondrial genomes grew faster in liquid as compared to the pAGE3.0 control, but at a similar rate when compared to the pPtGE31 control (Figure 3C). Overall, this indicates that the maintenance of $P$. tricornutum's mitochondrial genomes plasmids does not have an adverse effect on yeast growth. In E. coli, we did 
bioRxiv preprint doi: https://doi.org/10.1101/2019.12.19.882662; this version posted December 19, 2019. The copyright holder for this preprint (which was not certified by peer review) is the author/funder, who has granted bioRxiv a license to display the preprint in perpetuity. It is made available under aCC-BY-NC-ND 4.0 International license.

not observe any substantial negative effects on growth rates of cells harbouring P. tricorunutm's mitochondrial genomes, as compared to the control plasmids (Figure 3B and D). In addition, there was no substantial effect on growth rates when the cells were induced to have high copy number of mitochondrial genomes.

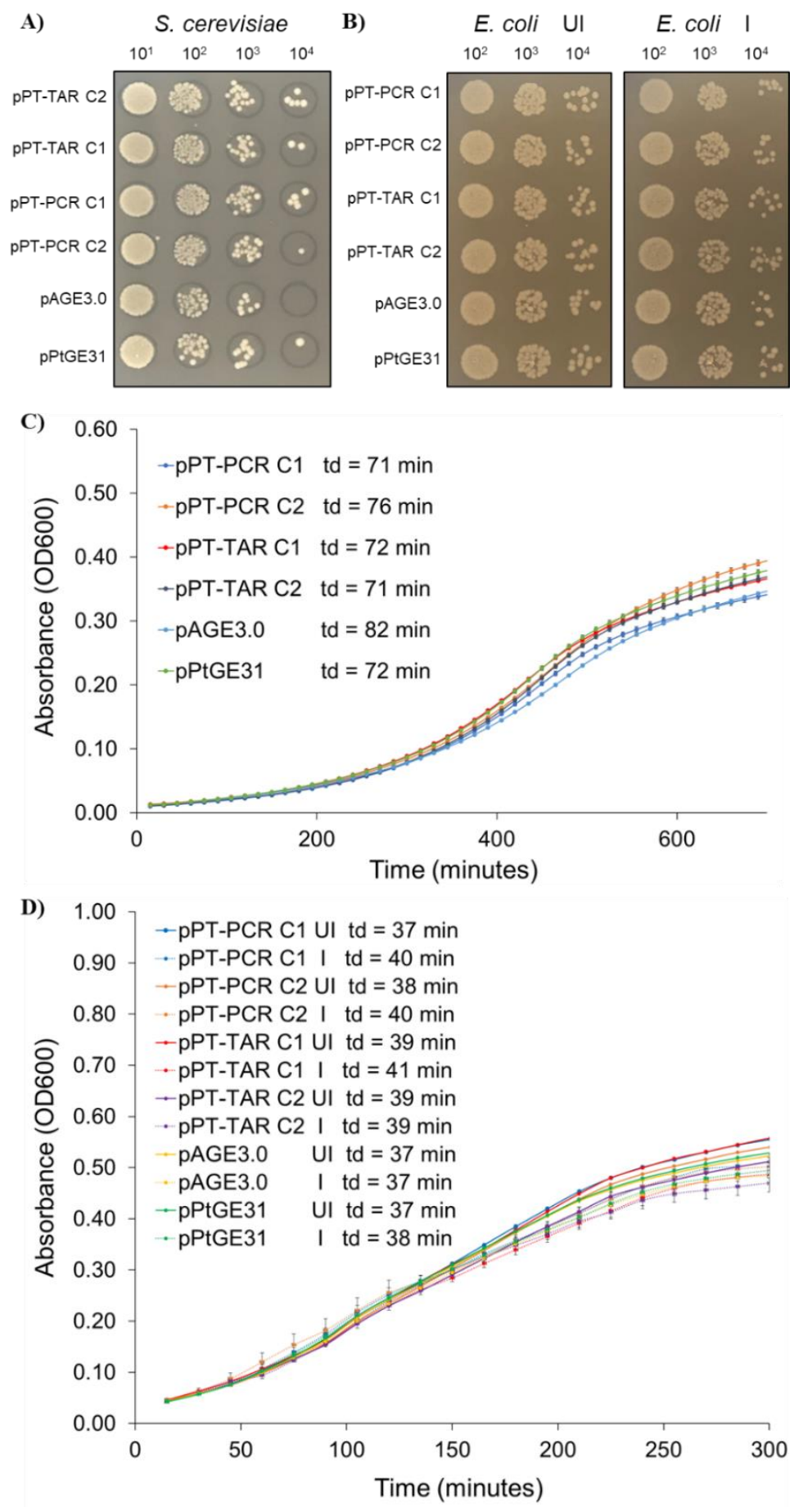


Figure 3. Analysis of growth of S. cerevisiae and E. coli strains harbouring cloned P. tricornutum mitochondrial genomes on solid media and in liquid media. A) Dilutions $\left(10^{1}-10^{4}\right)$ of $S$. cerevisiae strains plated on solid synthetic complete media lacking histidine. B) Dilutions $\left(10^{2}-10^{4}\right)$ of E. coli strains plated on solid LB media supplemented with chloramphenicol only (UI - uninduced) or with chloramphenicol and arabinose (I - induced) to increase plasmid copy number. C) Growth curves of $S$. cerevisiae strains grown in liquid synthetic complete media lacking histidine. D) Growth curves of $E$. coli grown in liquid LB media supplemented with chloramphenicol only (UI) or with chloramphenicol and arabinose (I). Td: doubling time.

\section{Conclusions}

The biotechnological potential of organelle engineering is held back by the lack of reliable methods to replace organellar genomes. Towards the goal of establishing a design-build-test cycle for genome-scale organelle engineering, we have developed two adaptable methods for cloning and manipulating eukaryotic mitochondrial genomes. With a PCR-based approach, we cloned a variant of the P. tricornutum mitochondrial genome lacking its 35-kbp repeat region and with a TAR-based approach, we captured the complete genome. The former had a mutation rate ranging from 1 mutation per 8.6-20 kbp, while the latter allowed us to identify one clone with only a single mutation. The cloned genomes imposed no substantial growth burden on S. cerevisiae and E. coli when these host organisms were used to propagate the plasmids. In this study, we completed the first step in developing a reproducible set of methods for cloning, manipulating, and installing synthetic organelle genomes. 


\section{Acknowledgements}

This work was supported by Natural Sciences and Engineering Research Council of Canada (RGPIN-2018-06172) awarded to B.J.K. Salary for P.J. was supported by Designer Microbes Inc. (DMI). In addition, research in D.R.E., is also supported by Natural Sciences and Engineering Research Council of Canada (NSERC), RGPIN-2015-04800.

\section{Declaration of Competing Interest}

Conflicts of Interest: B.J.K. is Chief Executive Officer of Designer Microbes Inc. B.J.K and P.J. hold Designer Microbes Inc. stock.

\section{Authorship Contributions}

Ryan R. Cochrane: Formal analysis, Investigation, Methodology, Validation, Visualization, Roles/Writing - original draft; Writing - review \& editing.; Stephanie L. Brumwell: Formal analysis, Investigation, Validation, Visualization, Roles/Writing - original draft, Writing review \& editing.; Maximillian P.M. Soltysiak: Investigation, Validation, Writing - review \& editing.; Samir Hamadache: Formal analysis, Investigation, Validation, Visualization, Writing review \& editing.; Jennifer G. Davis: Investigation.; Jiayi Wang: Investigation.; Samuel Q. Tholl: Investigation.; Preetam Janakirama: Investigation.; David R. Edgell: Resources, Supervision, Writing - review \& editing.; Bogumil J. Karas: Conceptualization, Funding acquisition, Investigation, Methodology, Project administration, Resources, Supervision, Validation, Visualization, Roles/Writing - original draft, Writing - review \& editing. 


\section{Appendix A. Supplementary Data}

Supplementary data to this article can be found online

\section{REFERENCES}

1. Scaife MA, Smith AG. Towards developing algal synthetic biology. Biochem Soc Trans. 2016. doi:10.1042/BST20160061

2. Adarme-Vega TC, Lim DKY, Timmins M, Vernen F, Li Y, Schenk PM. Microalgal biofactories: a promising approach towards sustainable omega-3 fatty acid production. Microbial Cell Factories. 2012. doi:10.1186/1475-2859-11-96

3. Brasil B dos SAF, de Siqueira FG, Salum TFC, Zanette CM, Spier MR. Microalgae and cyanobacteria as enzyme biofactories. Algal Research. 2017.

doi:10.1016/j.algal.2017.04.035

4. Hlavova M, Turoczy Z, Bisova K. Improving microalgae for biotechnology - From genetics to synthetic biology. Biotechnology Advances. 2015. doi:10.1016/j.biotechadv.2015.01.009

5. Rosales-Mendoza S, Angulo C, Meza B. Food-grade organisms as vaccine biofactories and oral delivery vehicles. Trends in Biotechnology. 2016. doi:10.1016/j.tibtech.2015.11.007

6. Slattery SS, Diamond A, Wang H, Therrien JA, Lant JT, Jazey T, et al. An Expanded Plasmid-Based Genetic Toolbox Enables Cas9 Genome Editing and Stable Maintenance of Synthetic Pathways in Phaeodactylum tricornutum. ACS Synth Biol. 2018;7: 328-338. doi:10.1021/acssynbio.7b00191

7. Yongmanitchai W, Ward OP. Growth of and omega-3 fatty acid production by Phaeodactylum tricornutum under different culture conditions. Appl Environ Microbiol. 1991. 
8. Bowler C, Allen AE, Badger JH, Grimwood J, Jabbari K, Kuo A, et al. The Phaeodactylum genome reveals the evolutionary history of diatom genomes. Nature. 2008. doi:10.1038/nature07410

9. Oudot-Le Secq MP, Green BR. Complex repeat structures and novel features in the mitochondrial genomes of the diatoms Phaeodactylum tricornutum and Thalassiosira pseudonana. Gene. 2011;476: 20-26. doi:10.1016/j.gene.2011.02.001

10. Oudot-Le Secq M-P, Grimwood J, Shapiro H, Armbrust · E Virginia, Bowler C, Green BR. Chloroplast genomes of the diatoms Phaeodactylum tricornutum and Thalassiosira pseudonana: comparison with other plastid genomes of the red lineage. Mol Genet Genomics. 2007;277: 427-439. doi:10.1007/s00438-006-0199-4

11. Apt KE, Kroth-Pancic PG, Grossman AR. Stable nuclear transformation of the diatom Phaeodactylum tricornutum. Mol Gen Genet. 1996. doi:10.1007/s004380050264

12. Falciatore A, Casotti R, Leblanc C, Abrescia C, Bowler C. Transformation of nonselectable reporter genes in marine diatoms. Mar Biotechnol. 1999. doi:10.1007/PL00011773

13. Zhang $\mathrm{C}, \mathrm{Hu} \mathrm{H}$. High-efficiency nuclear transformation of the diatom Phaeodactylum tricornutum by electroporation. Mar Genomics. 2014. doi:10.1016/j.margen.2013.10.003

14. Miyahara M, Aoi M, Inoue-Kashino N, Kashino Y, Ifuku K. Highly efficient transformation of the diatom phaeodactylum tricornutum by multi-pulse electroporation. Biosci Biotechnol Biochem. 2013. doi:10.1271/bbb.120936

15. Miyagawa A, Okami T, Kira N, Yamaguchi H, Ohnishi K, Adachi M. Research note: High efficiency transformation of the diatom Phaeodactylum tricornutum with a promoter from the diatom Cylindrotheca fusiformis. Phycological Research. 2009. doi:10.1111/j.14401835.2009.00531.x

16. Karas BJ, Diner RE, Lefebvre SC, McQuaid J, Phillips APR, Noddings CM, et al. Designer 
diatom episomes delivered by bacterial conjugation. Nat Commun. 2015;6.

doi:10.1038/ncomms7925

17. Brumwell SL, Macleod Id MR, Huang T, Cochrane RR, Meaney RS, Zamani M, et al. Designer Sinorhizobium meliloti strains and multi-functional vectors enable direct interkingdom DNA transfer. PLoS One. 2019;14: e0206781. doi:10.1371/journal.pone.0206781

18. Karas BJ, Molparia B, Jablanovic J, Hermann WJ, Lin Y-C, Dupont CL, et al. Assembly of eukaryotic algal chromosomes in yeast. J Biol Eng. 2013;7: 30. doi:10.1186/1754-1611-730

19. Diner RE, Noddings CM, Lian NC, Kang AK, McQuaid JB, Jablanovic J, et al. Diatom centromeres suggest a mechanism for nuclear DNA acquisition. Proc Natl Acad Sci U S A. 2017;114: E6015-E6024. doi:10.1073/pnas.1700764114

20. Wang H, Slattery S, Karas B, Edgell D. Delivery of the Cas9 or TevCas9 System into Phaeodactylum tricornutum via Conjugation of Plasmids from a Bacterial Donor. BIOPROTOCOL. 2018;8. doi:10.21769/bioprotoc.2974

21. Weyman PD, Beeri K, Lefebvre SC, Rivera J, Mccarthy JK, Heuberger AL, et al. Inactivation of Phaeodactylum tricornutum urease gene using transcription activator-like effector nuclease-based targeted mutagenesis. Plant Biotechnol J. 2015. doi:10.1111/pbi. 12254

22. Siaut M, Heijde M, Mangogna M, Montsant A, Coesel S, Allen A, et al. Molecular toolbox for studying diatom biology in Phaeodactylum tricornutum. Gene. 2007. doi:10.1016/j.gene.2007.05.022

23. Avalos JL, Fink GR, Stephanopoulos G. Compartmentalization of metabolic pathways in yeast mitochondria improves the production of branched-chain alcohols. Nat Biotechnol. 2013. doi:10.1038/nbt.2509 
24. Bigger BW, Liao AY, Sergijenko A, Coutelle C. Trial and error: How the unclonable human mitochondrial genome was cloned in yeast. Pharm Res. 2011. doi:10.1007/s11095011-0527-1

25. Yoon YG, Koob MD. Efficient cloning and engineering of entire mitochondrial genomes in Escherichia coli and transfer into transcriptionally active mitochondria. Nucleic Acids Research. 2003. doi:10.1093/nar/gkg228

26. Gibson DG, Smith HO, Hutchison CA, Venter JC, Merryman C. Chemical synthesis of the mouse mitochondrial genome. Nat Methods. 2010. doi:10.1038/nmeth.1515

27. Gupta M, Hoo B. Entire maize chloroplast genome is stably maintained in a yeast artificial chromosome. Plant Mol Biol. 1991. doi:10.1007/BF00040631

28. Itaya M, Fujita K, Kuroki A, Tsuge K. Bottom-up genome assembly using the Bacillus subtilis genome vector. Nat Methods. 2008;5: 41-43. doi:10.1038/nmeth1143

29. O’Neill BM, Mikkelson KL, Gutierrez NM, Cunningham JL, Wolff KL, Szyjka SJ, et al. An exogenous chloroplast genome for complex sequence manipulation in algae. Nucleic Acids Res. 2012. doi:10.1093/nar/gkr1008

30. Ostrov N, Landon M, Guell M, Kuznetsov G, Teramoto J, Cervantes N, et al. Design, synthesis, and testing toward a 57-codon genome. Science (80- ). 2016;353: 819-822. doi:10.1126/science.aaf3639

31. Fredens J, Wang K, de la Torre D, Funke LFH, Robertson WE, Christova Y, et al. Total synthesis of Escherichia coli with a recoded genome. Nature. 2019. doi:10.1038/s41586019-1192-5

32. Gibson DG, Glass JI, Lartigue C, Noskov VN, Chuang RY, Algire MA, et al. Creation of a bacterial cell controlled by a chemically synthesized genome. Science (80- ). 2010. doi:10.1126/science. 1190719 
33. Lartigue C, Glass JI, Alperovich N, Pieper R, Parmar PP, Hutchison CA, et al. Genome transplantation in bacteria: Changing one species to another. Science (80- ). 2007. doi:10.1126/science. 1144622

34. Hutchison CA, Chuang RY, Noskov VN, Assad-Garcia N, Deerinck TJ, Ellisman MH, et al. Design and synthesis of a minimal bacterial genome. Science (80- ). 2016. doi:10.1126/science.aad6253

35. Richardson SM, Mitchell LA, Stracquadanio G, Yang K, Dymond JS, DiCarlo JE, et al. Design of a synthetic yeast genome. Science (80- ). 2017;355: 1040-1044. doi:10.1126/science.aaf4557

36. Ostrov N, Beal J, Ellis T, Benjamin Gordon D, Karas BJ, Lee HH, et al. Technological challenges and milestones for writing genomes. Science. American Association for the Advancement of Science; 2019. pp. 310-312. doi:10.1126/science.aay0339

37. Karas BJ, Tagwerker C, Yonemoto IT, Hutchison CA, Smith HO. Cloning the Acholeplasma laidlawii PG-8A Genome in Saccharomyces cerevisiae as a Yeast Centromeric Plasmid. ACS Synth Biol. 2012;1: 22-28. doi:10.1021/sb200013j

38. Karas BJ, Jablanovic J, Sun L, Ma L, Goldgof GM, Stam J, et al. Direct transfer of whole genomes from bacteria to yeast. Nat Methods. 2013;10: 410-412. doi:10.1038/nmeth.2433

39. Lee NCO, Larionov V, Kouprina N. Highly efficient CRISPR/Cas9-mediated TAR cloning of genes and chromosomal loci from complex genomes in yeast. Nucleic Acids Res. 2015. doi:10.1093/nar/gkv112

40. Ruiz E, Talenton V, Dubrana M-P, Guesdon G, Lluch-Senar M, Salin F, et al. CReasPycloning: a method for simultaneous cloning and engineering of 2 megabase-sized genomes in yeast using the CRISPR-Cas9 system. ACS Synth Biol. 2019;8: 2547-2557. doi:10.1021/acssynbio.9b00224 
41. Soltysiak MPM, Meaney RS, Hamadache S, Janakirama P, Edgell DR, Karas BJ. Transkingdom conjugation within solid media from Escherichia coli to Saccharomyces cerevisiae. Int J Mol Sci 2019, Vol 20, Page 5212. 2019;20: 5212.

doi:10.3390/IJMS20205212

42. Karas BJ, Suzuki Y, Weyman PD. Strategies for cloning and manipulating natural and synthetic chromosomes. Chromosom Res. 2015. doi:10.1007/s10577-014-9455-3 